\title{
Montaje, tramas paralelas e ironía dramática en el relato cinematogiráfico
}

\author{
Diego Alonso Sarmiento Herencia \\ diego.sarmiento@unmsm.edu.pe
}

\section{Resumen}

El cine es un fenómeno narrativo aún joven. Y dado que su desarrollo ha sido - y sigue siendo - vertiginoso, es, a veces, muy difícil de explicar. Los distintos elementos que participan en el desarrollo de historias - imágenes, sonidos, montaje, etc.- son tantos y tan variados que pretender explicarlos o definirlos es una tarea muy grande para un solo documento. Este artículo apunta a identificar y describir, desde las relaciones entre cine y literatura $-\mathrm{y}$ desde un ángulo estructural- las técnicas de montaje, construcción de tramas paralelas y la ironía dramática; todas ellas importantes componentes del cine moderno.

Palabras clave: Literatura, cine, montaje, tramas paralelas, estructura, ironía.

\begin{abstract}
Cinema is young narrative phenomenon. Given that its development has been —and continues to be - vertiginous, it is, sometimes, quite difficult to explain. The different elements that play a part in the development of stories -images, sounds, montage, etc.- - are so many and so different that to explain or define them is too grand a chore for a single document. This paper aims at identifying and describing, from the relations between cinema and literature, and from an structural point of view, the montage technics, the construction of parallel storylines and dramatic irony, all of which are important components of modern cinema.
\end{abstract}

Key words: Literature, cinema, montage, parallel storylines, structure. 


\section{Montaje, tramas paralelas e ironía dramática en el relato cinematogiráfico}

\section{Introducción}

¿Qué tienen en común los mejores relatos, poemas, películas o series? Estructuras sólidas. La estructura es cimiento, más allá del tema o los personajes. Como decía Alexander McKendrick "Los guiones son ESTRUCTURA, ESTRUCTURA, ESTRUCTURA." ${ }^{1}$. Muchas veces, incluso, existe antes que la trama, como un esqueleto sobre el cual se inscriben elementos que conforman al final la historia.

¿Por qué es tan importante para el cine? Porque permite organizar una historia con economía. Permite mantener a los espectadores atentos. Es por eso que el estudio de la estructura es imprescindible para cineastas y guionistas. Pero, como se dijo anteriormente, la estructura es el esqueleto. Un esqueleto tan vacío como el del cuerpo humano años después de la muerte. Y casi tan vacío como las tramas sin historia.

Las historias que se cuentan, los personajes que se nos presentan, los mundos que exploramos... ahí está finalmente la magia. Y la magia del cine empieza con en el montaje: una herramienta cinematográfica que no es nada ajena a la literatura, como veremos a continuación.

\section{El montaje}

La palabra montaje y su uso en el cine viene del francés montage, que no significa otra cosa que ensamblar, instalar. En el mundo cinematográfico, se refiere a la edición. En el cine soviético de la década de 1920, el montaje era visto como el método de yuxtaponer planos unos a continuación de otros con el fin de generar nuevos significados que no existían antes de este proceso, con los planos independientes.

Habiendo ya grabado el material, habiéndolo filmado, podemos proyectarlo. [...] Antes de que sea posible mostrar las partes, es imprescindible 
editarlas, unirlas unas a otras para que las inter relaciones demuestren la esencia del fenómeno que nos rodea.

[...] Así, el montaje, como todo el trabajo cinematográfico, está indisolublemente ligado a la visión del artista y a sus propósitos ideológicos ${ }^{2}$ (Kuleshov, 1974, p.184)

En la tradición clásica de Hollywood, una secuencia de montaje se refiere a un segmento corto de una película en el que se le presenta información al espectador de manera rápida y condensada. Sin embargo, lo más interesante - e importante- del proceso de montaje o edición es que es la única etapa de la creación cinematográfica que es propia del mundo del cine. Vsevolod Pudovkin, director, guionista y actor soviético — además de haber sido un importante teórico del montaje - remarcaba ese factor, dado que todos los demás aspectos de la manufactura de películas eran prestados de otras artes - fotografía, artes plásticas, literatura, música y grabación de sonido. Curioso es también que el famoso y exitoso director Stanley Kubrick era un apasionado de la edición y consideraba que todo lo que la precedía no era más que una manera de conseguir material para editar.

Sobre este aspecto, citamos al reputado escritor y director estadounidense Preston Sturges, responsable de la premiada The Great McGinty (1940):

Hay una norma en hacer el corte natural, y es replicar lo que la audiencia en un teatro hace por sí sola. Mientras más se acerca a esta norma de interés natural, más invisible será el corte realizado por el cortador. Si la cámara corta de una persona a otra en el momento exacto en que ese espectador en el teatro hubiera volteado legítimamente su cabeza, uno no será consciente de ese corte. En cambio, si la cámara demora por un cuarto de segundo, habrá un sobresalto. Hay otro requerimiento: ambas tomas deben tener el mismo valor tonal aproximado. Si se corta de negro a blanco, es discordante. En todo momento la cámara debe ver el punto exacto que la audiencia vería. Encontrar ese lugar es absurdamente fácil: uno solo debe recordar hacia dónde es que uno estaba mirando cuando la escena fue hecha. ${ }^{3}$ (Sturges, 1991, p.275)

Por supuesto, eso es una exagerada simplificación dado que el montaje es, en realidad, un fenómeno muchísimo más importante y complejo.

En la década de 1910, Kuleshov editó una pequeña película en la que un actor, el ídolo soviético Ivan Mosjoukine, se mostraba completamente inexpresivo mientras su imagen alternaba con distintas tomas - un plato de sopa, una niña en un ataúd y una mujer en un diván. Dicha película fue mostrada ante una audiencia y los resultados fueron increíbles. Ellos creyeron que la expresión en el rostro de Mosjoukine era diferente cada una de las veces que se mostraba, dependiendo de con qué pieza de película estuviera conectada. Con el plato de 
sopa, era un rostro de hambre; con la niña en el ataúd, duelo; finalmente con la mujer en el diván era deseo. Sin embargo, el material fílmico de Mosjoukine había sido siempre el mismo (Loza, 2012).

Digamos que un actor está dando una interpretación para un momento lúgubre; usted filma su rostro demacrado. Ese rostro ha sido filmado en el Marco de un "contexto lúgubre". Pero existen instancias en que aquel rostro filmado para una escena lúgubre, por su composición, puede resultar adecuado para una escena alegre. Con la ayuda del montaje, dicho rostro puede ser editado en la escena, y sucede que una interpretación particular de un actor obtiene un significado completamente distinto gracias al montaje. ${ }^{4}$ (Kuleshov, 1974, p.192)

Kuleshov había demostrado que el montaje era la herramienta más necesaria del arte cinematográfico. Según Kuleshov el cine es el ensamblaje de fragmentos y elementos diferentes. Entonces no es el contenido de las imágenes en una película, lo más importante sino la manera en que se combinan unas con otras. El material crudo puede ser ensamblado y desensamblado una y otra vez en distintas yuxtaposiciones creando un nuevo sentido.

Otros experimentos posteriores, cimentarían aún más la importancia del montaje en el cine. Es el caso de la alteración al orden de los elementos y la "geografía creativa" también llamada paisajes artificiales.

\section{Las tramas paralelas}

Las tramas paralelas, conocidas también como narrativas paralelas, describen a una estructura en la que el escritor construye dos o más relatos independientes unidos ya sea por un personaje, un evento o un tema común. Las tramas paralelas vienen siendo utilizadas por dramaturgos y novelistas desde los inicios del arte narrativo (Aronson, 2011b).

La característica principal de una historia con tramas paralelas es que es no lineal. Una trama lineal sigue a uno o más personajes a lo largo de la historia, desde el conflicto hasta su solución, en orden cronológico. Una trama no lineal salta entre líneas de tiempo y personajes. No existe un patrón específico pues la estructura variará dependiendo del propósito de las narrativas paralelas - generar tensión, producir ironía dramática, solucionar un misterio, revelar motivaciones en los personajes o simplemente dar a conocer distintas perspectivas-.

El patrón más común es la combinación de dos tramas en la que dos historias separadas son contadas en la misma novela. Estas se pueden contar en secuencia, una después de la otra, o pueden ser entretejidas en una especie de trenza. En líneas generales, los acontecimientos de las dos tramas se dan en 
paralelo a lo largo de la novela y se combinan en el clímax o en la resolución de la historia.

En sus Cartas a un joven novelista, Vargas Llosa habla de un procedimiento, el último: Los "vasos comunicantes". Vargas Llosa explica, utilizando los "comicios agrícolas", memorable episodio de Madame Bovary, en que, gracias al procedimiento, la situación representada entre los personajes durante la declaración de amor “... resulta menos grotesca y patética de lo que sería sin la presencia de ese filtro sensible, amortiguador del sarcasmo" (Vargas Llosa, 1997, p.87-88). Los “vasos comunicantes", como los llama Vargas Llosa, son el tejido de las tramas paralelas que tienen el poder de alterarse o modificarse entre sí, produciendo un relato nuevo, enriquecido.

Debido a esa conformación, los distintos sucesos, articulados en un sistema de vasos comunicantes, intercambian vivencias y se establece entre ellos una interacción gracias a la cual los episodios se funden en una unidad que hace de ellos algo distinto de meras anécdotas yuxtapuestas. (Vargas Llosa, 1997, p.87)

Otro ejemplo claro en la literatura lo podemos encontrar en «La noche boca arriba» de Cortázar.

Tal vez un animal que escapaba como él del olor a guerra. Se enderezó despacio, venteando. No se oía nada, pero el miedo seguía allí como el olor, ese incienso dulzón de la guerra florida. Había que seguir, llegar al corazón de la selva evitando las ciénagas. A tientas, agachándose a cada instante para tocar el suelo más duro de la calzada, dio algunos pasos. Hubiera querido echar a correr, pero los tembladerales palpitaban a su lado. En el sendero en tinieblas, buscó el rumbo. Entonces sintió una bocanada del olor que más temía, y saltó desesperado hacia adelante.

— Se va a caer de la cama — dijo el enfermo de la cama de al lado—. No brinque tanto, amigazo.

Abrió los ojos y era de tarde, con el sol ya bajo en los ventanales de la larga sala. Mientras trataba de sonreír a su vecino, se despegó casi físicamente de la última visión de la pesadilla. El brazo, enyesado, colgaba de un aparato con pesas y poleas. Sintió sed, como si hubiera estado corriendo kilómetros, pero no querían darle mucha agua, apenas para mojarse los labios y hacer un buche (...) Vio llegar un carrito blanco que pusieron al lado de su cama, una enfermera rubia le frotó con alcohol la cara anterior del muslo, y le clavó una gruesa aguja conectada con un tubo que subía hasta un frasco lleno de líquido opalino. Un médico joven vino con un aparato de metal y cuero que le ajustó al brazo sano para verificar alguna cosa. (Cortázar, 1964, p.85) 
En este cuento se nos presentan dos historias paralelas: La de un joven que estuvo involucrado en un accidente de motocicleta y está ahora tendido en una cama de un hospital; la otra, la de un joven moteca a punto de ser sacrificado. Ambas se narran a la par, dentro del mismo texto, pero respetando los límites ficcionales de cada una de ellas.

En el cine, podemos encontrar tres formas lineales y tres no lineales de trabajar con tramas paralelas. Las lineales son: Narrativa en tándem, protagonistas múltiples y travesía doble (Aronson, 2011a).

En las películas con narrativa en tándem, encontramos historias del mismo peso avanzando en simultáneo. Se sostienen haciendo uso de una serie de herramientas, como el usar una "trama macro". Un ejemplo es Short Cuts (1993) escrita por Frank Barhydt y Robert Altman y dirigida por el segundo. En las películas con protagonistas múltiples, el protagonista suele ser un grupo, un equipo. Aquí se suelen encontrar todas las películas acerca de familias. Ejemplos de este tipo de películas son Todo sobre mi madre (1999) escrita y dirigida por Pedro Almodóvar y The full Monty (1997) escrita por Simon Beaufoy y dirigida por Peter Cattaneo. Finalmente, antes de pasar a las formas no lineales, están las películas de travesía doble. En ellas suelen haber dos protagonistas igual de importantes, avanzando a través de la historia física o emocionalmente - o ambas - ya sea el uno hacia el otro, en sentidos opuestos o en paralelo. Dado que se les ve por separado, interactuando con otros personajes, cada uno necesita su propia trama. Ejemplos de esta forma son The departed (2006) escrita por William Monahan —basada en el Thriller hongkonés Infernal Affairs (2002) - y dirigida por Martin Scorsese o Finding Nemo (2003), escrita por Andrew Stanton, Bob Peterson y David Reynolds y dirigida por el primero.

Las formas no lineales en las tramas paralelas usan a menudo saltos en el tiempo creando tramas fracturadas. Ellas son: el flashback, las historias consecutivas y tándem fracturado (Aronson, 2011a).

El flashback es muchas veces visto como una simple herramienta para construir historia pasada que nos ayude a entender un acontecimiento actual en la trama. Sin embargo va bastante más allá. Nos permite, por ejemplo, mostrar fragmentos no cronológicos de una relación o aventura pasada que no tuvo éxito, ir develando, paulatinamente un acontecimiento del pasado que afecta al presente de la historia siendo contada o empezar en el presente, cuando la historia ya acabó para retroceder luego y avanzar cronológicamente hasta encontrarnos nuevamente en la escena inicial, como, por ejemplo, en Saving Private Ryan (1998) escrita por Robert Rodat y dirigida por Steven Spielberg o en Fight Club (1996) escrita por Jim Uhls —basada en la novela homónima de Chuck Palahniuk-y dirigida por David Fincher.

Las historias consecutivas - algo así como narrativas en secuencia- son aquellas que funcionan independientemente unas de otras, pero que están en 
la película en secuencia una atrás de otra. Dentro de este tipo de estructura encontramos a Pulp Fiction (1994), dirigida por Quentin Tarantino y escrita en conjunto por él y Roger Avary, cuya estrutura es sumamente interesante por el hecho de que una de las historias funciona como un contenedor de las otras. Dentro de este tipo de estructura también encontramos a aquellas historias que se suceden para conectarse recién al final, ya sean distintas perspectivas de la misma historia — distintos puntos de vista de los mismos eventos- o distintas consecuencias.

La estructura de tándem fracturado la encontramos en películas como 21 grams (2003) y Babel (2006) ambas escritas por Guillermo Arriaga y dirigidas por Alejandro González Iñárritu o The Hours (2002), escrita por David Hare - basada en la novela homónima de Michael Cunningham- y dirigida por Stephen Daldry. Las historias en estas películas suelen suceder en distintos tiempos y están fracturadas, truncadas, en la manera en que estructuralmente están construidas, generando suspenso desde un inicio. Logran generar conexiones inesperadas - usualmente trágicas - entre personajes que aparentemente estaban desconectados siendo el gatillo para estas situaciones, accidentes o eventos azarosos.

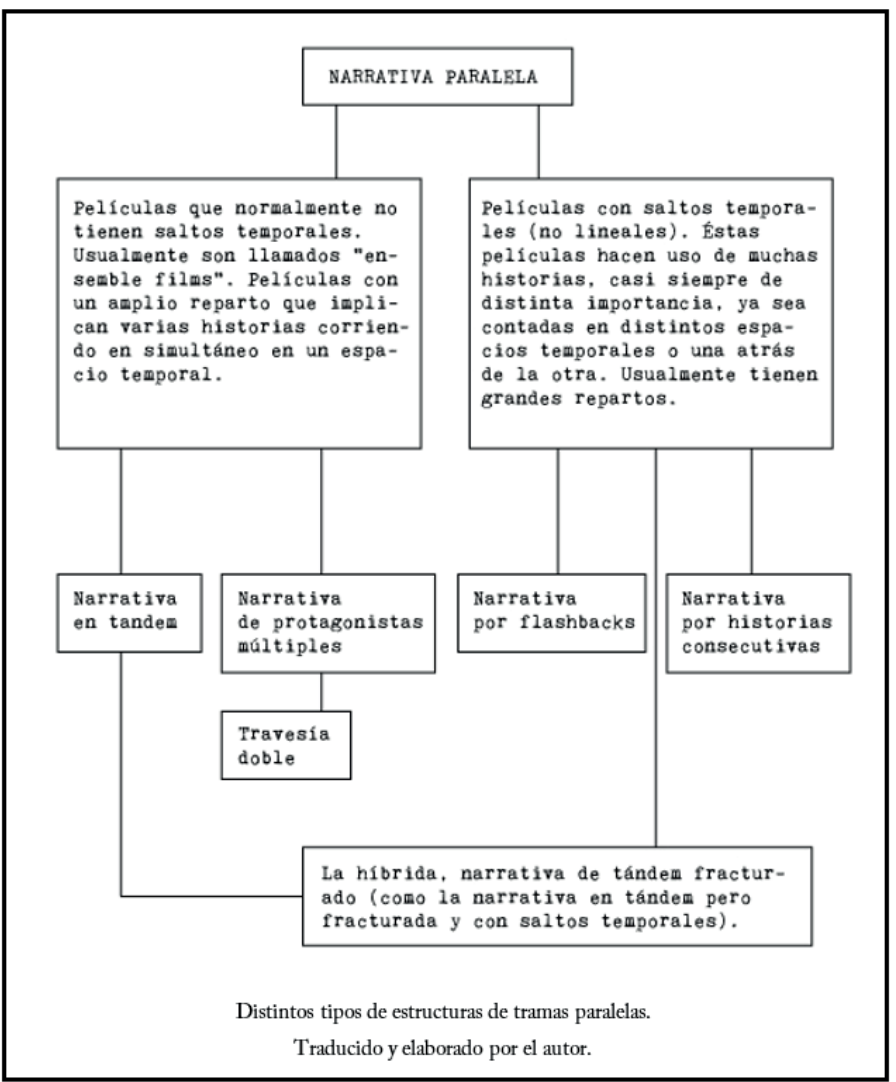


Definitivamente es una de las formas más emocionantes para escritores dado que se pueden utilizar para contar o acomodar momentos en las películas con el fin de sostener el suspenso o generar una expectativa en el espectador. En The Hours, por ejemplo, la normalidad de cada uno de los personajes es de vital importancia para la historia, sin embargo, mostrarla podría terminar siendo bastante aburrido para el espectador de no ser por el flashforward. Gracias a él, se sostienen estas tres historias que suceden un mismo día en tres años distintos: En 1923 Virginia Woolf ha empezado a escribir Mrs. Dalloway; en 1951, una ama de casa con problemas en Los Ángeles escapa de su convencional vida leyendo Mrs. Dalloway y, finalmente, en 2001 Clarissa Vaughan, en Nueva York, es la versión moderna de la protagonista de la novela - Clarissa Dalloway - antes mencionada, ocupa su día organizando una fiesta en honor de un ex-amante, su amigo Richard, un poeta y autor con SIDA que pronto va a recibir un importante premio literario.

Este tipo de estructuras es común en el cine, y como se ha visto en los casos de The Hours y Fight Club ambas basadas en novelas literarias, vienen de la literatura y su uso es común y bastante anterior a la aparición del cine. Las encontramos en Shakespeare -A Midsummer Night's Dream y The Merchant of Venice- en A Study in Scarlet de Sir Arthur Conan Doyle o en The Sound and the Fury de William Faulkner.

Más allá de todo lo expuesto, el aspecto más interesante de las estructuras de tramas paralelas es que estas obligan a los escritores a salir de la comodidad de construir historias en base a estructuras fijas, sin cambios ni apuestas. Historias de este tipo han transformado las ideas sobre qué tipos de historias prefiere el público.

\section{La ironía}

De acuerdo al diccionario de la Real Academia de la Lengua Española, en su tercera acepción, la ironía es una expresión que da a entender algo contrario o diferente de lo que se dice, generalmente como burla disimulada (RAE, 2017). En la literatura se refiere a un recurso donde las palabras se usan con el fin de expresar un significado no literal de manera intencionada. No debe ser confundida con el sarcasmo, un tipo cruel de ironía que busca descalificar moralmente a quien la recibe.

Según Schoentjes (2003) existen cuatro categorías de ironía: la socrática, una ironía dialéctica que busca la verdad mediante alegorías; la ironía de situación, de corte dramático que pretende mostrar la vida con base en la peripecia; la ironía verbal, retórica que intenta convencer, producir el contrario mediante antífrasis; y la romántica, aquella que por medio de parábasis consigue su fin estético. Para fines de esta investigación, nos concentraremos en la 
ironía de situación, y con más detalle aún, en la ironía dramática (Schoentjes, 2003, p.45).

Una manera sencilla de definir la ironía de situación es decir que es la diferencia entre lo que uno espera que suceda y lo que finalmente sucede. Un ejemplo claro lo encontramos en Great Expectations, de Charles Dickens. Pip, un huérfano criado por su hermana Georgina, no sabe quién es su benefactor. Los lectores tampoco. De hecho, conforme avanza la novela se nos lleva a creer que, de hecho, la benefactora es la señorita Havisham, sin embargo, al cierre descubrimos que el benefactor no era otro que Magwich, el convicto a quien Pip le mostró amabilidad y compasión desde muy joven. Descubrir esto va en contra de las expectativas de Pip y de las del público lector; eso es ironía de situación.

\section{La ironía dramática}

La ironía dramática, por otro lado, a pesar de formar parte de la ironía de situación, se da cuando al público se le proporciona información que el personaje principal de la escena no conoce (Schoentjes, 2003, p.52).

Desde que el público entiende que hay mucho más allá de los personajes en la historia, se alteran los significados de las acciones y de los diálogos de ellos. Este conocimiento puede generar suspenso o, en algunos casos, comedia. Pongámonos por un momento en el lugar de los personajes, desconocedores ellos de "la verdad". Empezaremos a tomar decisiones que, a los ojos del público, son inapropiadas o incluso tontas. El beneficio de dichos malentendidos es que se pueden crear nuevos conflictos haciendo avanzar la historia. Shakespeare fue un cultor de esta técnica.

En La tragedia de Julio César, cuando Bruto está pensando aún si se une o no a la conspiración contra el César, son las cartas que recibe — aparentemente escritas por ciudadanos de Roma, pidiéndole, casi rogándole, que anule el poder de César- las que lo empujan a unirse a la conspiración. El público sabe, sin embargo, que esas cartas fueron escritas por Cassius, quien busca obtener algo del poder del César.

Otro ejemplo es el del final de Romeo y Julieta. El público sabe que ella ha bebido una poción que la hace parecer muerta. La ironía dramática existe porque Romeo, a diferencia de los espectadores, no tiene esa información. En cine Hitchcock ejemplifica muy bien la ironía dramática en el suspenso con su ejercicio de "la bomba bajo la mesa". Él decía que si veíamos a una pareja sentada alrededor de una mesa debajo de la cual hay una bomba, de la cual ni ellos ni nosotros como espectadores sabemos, y la bomba de pronto explota, eso generará un gran momento climático de sorpresa. Por otro lado, si nosotros como espectadores sabemos de la bomba, pero no lo saben los personajes, permaneceremos en tensión durante todo el tiempo que dure la escena, invadidos 
por una mezcla de entre temor y esperanza. Vemos aquí también una pequeña aparición de la trama paralela: lo que sucede bajo la mesa versus lo que sucede sobre ella; ambas partes se complementan y construyen un relato interesante que es la base de las historias del cine moderno.

Para cerrar el tema, viéndolo desde lejos, Mackendrick (2004, pp. 76-80) nos dice en su ejercicio de estructuración de guiones "Once upon a time..." que la ironía dramática aparece junto a las tramas paralelas "But meanwbile... So unbeknownst..." . Dicho ejercicio está basado en la clásica estructura del cuento para niños.

\section{Conclusiones}

El cine sin montaje sería cualquier otra cosa; Un experimento casi teatral aunque carente de convivio y de la riqueza de la transformación constante. Así, el montaje es una herramienta básica del cine, y el proceso que lo distingue de todas las otras artes de las que "robó", es la herramienta principal en la narración cinematográfica, la que permite tejer las tramas de distintas maneras de tal forma que el cineasta pueda moldear el sentido de la historia.

Las tramas paralelas son una consecuencia de la conversación entre cine y literatura y del uso del montaje en la narración. Son una fabricación estructural narrativa que permite agregar nuevas dimensiones a las historias a través de la manera en que se ensamblan dando dinamismo, nuevos sentidos, proporcionando información adicional o construyendo momentos memorables desde el tejido mismo narrativo, como con la ironía dramática, que permite sostener el suspenso en el espectador al proporcionarle combustible para a su natural sentido de anticipación. Es justamente la ironía dramática generada por el uso de tramas paralelas la que consigue mantener el interés del espectador en la historia - y la que termina de moldear los acontecimientos que vemos retratados en la trama que nos llevan hacia la conclusión de esta- ayudando a construir un relato interesante dentro de su natural construcción filosófica.

Así, podemos encontrar estos conceptos en la gran mayoría de películas que vemos en las carteleras - hoy en día virtuales-. Como una nota final, es importante reconocer la importancia del cine como entretenimiento en nuestros tiempos. La oferta en plataformas virtuales es grande porque la demanda por escapar a lugares y situaciones distintas a las del encierro son grandes. Vivimos un momento en el que hasta el teatro, uno de los padres del cine, se ha cinematizado, con el fin de alcanzar a las personas, ávidas de entretenimiento. Aplicando correctamente las herramientas del montaje, tramas paralelas e ironía dramática, herramientas antiguas, es posible construir el tipo de relato que satisfaga las nuevas necesidades de la audiencia. 


\section{Notas}

1 Traducción hecha por el autor. Texto original: "Screenplays are STRUCTURE, STRUCTURE, STRUCTURE”.

2 Traducción hecha por el autor. Texto original: "[...] Having recorded this material, having shot it, we can show it in the screen. [...] Before it is possible to show the different pieces photographed in reality, it is vital to edit them, to join them to each other so that the interrelationship demonstrates the essence on the phenomena around us.

[...] Thus, film montage, as the entire work of filmmaking, is inextricably linked to the artist's world-view and his ideological purpose”.

3 Traducción hecha por el autor. Texto original: "There is a law of natural cutting and that this replicates what an audience in a legitimate theater does for itself. The more nearly the film cutter approaches this law of natural interest, the more invisible will be his cutting. If the camera moves from one person to another at the exact moment that one in the legitimate theatre would have turned his head, one will not be conscious of a cut. If the camera misses by a quarter of a second, one will get a jolt. There is one other requirement: the two shots must be approximately of the same tone value. If one cuts from black to white, it is jarring. At any given moment, the camera must point at the exact spot the audience wishes to look at. To find that spot is absurdly easy: one has only to remember where one was looking at the time the scene was made".

4 Traducción hecha por el autor. Texto original: "Let us say that an actor is performing some sort of dismal moment; you film his drawn face. The face is shot in a setting of 'dismal context'. But there are instances when this face within a 'dismal' scene, by virtue of its compositional properties, is found to be suitable for a cheerful scene. With the help of montage, this face could be spliced into such scene, and instances do occur when a particular performance by an actor is given a totally different meaning through montage".

5 Traducción: "Pero mientras tanto... Sin que lo sepa..."

\section{Referencias bibliográficas}

Aronson, L. (2011a). 21st Century Screenplay: A Comprehensive Guide to Writing Tomorrow's Films. Allen \& Unwin. Kindle Edition.

Aronson L. (2011b). The six sorts of parallel narrative. Disponible en http://www. lindaaronson.com/six-types-of-parallel-narrative.html

Aronson L. (2011c) How Parallel Narrative Multiplies Your Story Choices. Disponible en http://www.lindaaronson.com/parallel-narrative.html

Cortázar, J (1964) Final del juego. Buenos Aires: Editorial Sudamericana.

Kuleshov, L. (1974). Kuleshov on film (Writings by Lev Kuleshov). Los Ángeles: University of California Press. Disponible en: https://books.google.com.pe/ books?id=0kfHxRVupxIC\&lpg=PR7\&pg=PP1\#v=onepage\&q\&f=false

Mackendrick, A. (2004). On Filmmaking (An Introduction to the craft of the Director). New York: Faber and Faber LTD.

Loza, N. (2012) El efecto Kuleshov explicado por Alfred Hitchcock. Norberto Loza. Disponible en https://www.youtube.com/watch?v=BpxYzs8hj3A 
Pudovkin, V. (1954). Film technique and Film acting. London: Vision.

Real Academia Española [RAE]. (2017). Ironía. Diccionario de la lengua española, 23 ed. Disponible en http://dle.rae.es/?id=M6heFtP

Schoentjes, P. (2003). La poética de la ironia. Madrid: Ediciones Cátedra.

Sturges, P. \& Sturges, S. (1991). Preston Sturges on Preston Sturges, Boston: Faber \& Faber.

Vargas Llosa, M. (1997). Cartas a un joven novelista. Barcelona: Planeta S.A. 